\title{
Comparison of mechanical properties of beta-titanium wires between leveled and unleveled brackets: an in vitro study
}

Natalia Martins Insabralde ${ }^{1}$, Thaís Poletti ${ }^{1}$, Ana Cláudia Conti ${ }^{1}$, Paula Vanessa Oltramari-Navarro ${ }^{1}$, Murilo B Lopes², Carlos Flores-Mir ${ }^{3}$ and Marcio Rodrigues de Almeida ${ }^{*}$

\begin{abstract}
Background: The objective of this study is to evaluate the force-deflection behavior of beta-titanium alloy wires between two leveled and unleveled bracket alignment scenarios using a three-point bending test.

Methods: Six groups of ten beta-titanium alloy wire segments $(0.017 \times 0.025$-in. diameter) of different manufacturers (Orthometric, Ortho Organizers, GAC, Morelli, and Ormco) were used. Both brackets were bonded to an acrylic jig with a 10-mm interbracket distance. A 1-mm deflection test in two hypothetical conditions (with aligned brackets and by simulating a 2-mm horizontal displacement of the brackets) was explored. Forces of activation and deactivation of the wires during both tests were compared by an analysis of variance (ANOVA) tests followed by a Tukey test.

Results: A statistically significant difference was found in the force-deflection behavior between some of the wires in both simulated in vitro conditions. For the leveled-type alignment scenario, the differences between wires were up to $70 \mathrm{~g}$ (range 110 to $179 \mathrm{~g}$ ). For the unleveled-type alignment scenario, these differences were up to $65 \mathrm{~g}$ (range 111 to $175 \mathrm{~g})$.

Conclusions: The study showed some significant differences in forces generated during activation and deactivation among the five types of beta-titanium wires tested. In comparing leveled and unleveled brackets during activation, only Orthometric Beta Flexy and Ormco Beta-titanium were different between them.
\end{abstract}

Keywords: Orthodontic wires; Beta-titanium; Three-point bending test

\section{Background}

Nowadays, orthodontists can select from among several available wire alloys the ones that better meet their specific demands on any given clinical situation. Thus, to be familiar with the mechanical properties and the clinical applications of those wire alloys is indispensable [1]. In fact, knowledge on the mechanics of an orthodontic system is essential in order to reach orthodontic results that are both desirable and predictable [2].

Beta-titanium ( $\beta$-Ti) alloy wires were first introduced in Orthodontics in 1979 [2,3]. These wires have gained great popularity over the past few years, due to their unique combination of properties (biocompatibility, resistance to

\footnotetext{
* Correspondence: marcioralmeida@uol.com.br

'Department of Orthodontics, University of North Parana, UNOPAR, Londrina, Paraná, Brazil

Full list of author information is available at the end of the article
}

corrosion, and low stiffness) [4]. Today, they are highly sought to make intrusion arches, cantilevers, and closing loops, by facilitating an individualized dental movement through controlled force systems [5]. The correct utilization of beta-titanium alloy wires can lead to a more efficient orthodontic tooth movement over a shorter period of time [6]. They may also be clinically adequate during the alignment and leveling of teeth throughout the orthodontic treatment [7]. The beta-titanium alloy wires provide an adequate combination of spring back, average stiffness, and good formability, therefore, providing a smaller permanent deformity of these wires [1]. Some authors concluded that an average low deflection force is beneficial for the initial phase of an orthodontic treatment, since it offers light and more constant forces and better precision in force application $[8,9]$. (c) 2014 Insabralde et al.; licensee Springer. This is an Open Access article distributed under the terms of the Creative Commons Attribution License (http://creativecommons.org/licenses/by/2.0), which permits unrestricted use, distribution, and reproduction in any medium, provided the original work is properly cited. 
A questionnaire about the action and applicability of beta-titanium alloys in clinical practice has been completed. It was found that the use of beta-titanium alloys is still growing as compared to stainless steel alloys, especially during the initial stages of treatment. While their use was of $13.5 \%$ in 2002, in 2008, it grew to $15.9 \%$. During the final stage of treatment, the use of betatitanium alloys was of $16.6 \%$ in 2002 and increased to $23.9 \%$ in 2008 . When introduced, these wires were used in loops and cantilevers within the segmented arch technique. Today, they are becoming popular in all phases of orthodontic treatment [10].

The modulus of elasticity of a wire describes the resistance of the material to flexion. It is considered the most important clinical parameter because it closely affects the biological nature of dental movement [11]. Various studies $[2-4,11,12]$ have evaluated orthodontic wires in laboratorial in vitro tests during deflection tests, in order to assess their load/deflection behavior and their elasticity module. All these studies used a set up where the brackets where dimensionally leveled and aligned. In an attempt to better simulate a different clinical situation, a 2-mm horizontal step between the brackets will be tested to evaluate if the load/deflection behavior changes. The objective of the study was therefore to evaluate the behavior of the deflection force, modulus of elasticity, and plastic deformation of five commercially available beta-titanium alloy wires between two leveled and unleveled bracket alignment scenarios using the three-point bending test.

\section{Methods}

The present study followed the ISO 15.841 guideline to perform orthodontics tests. As for the force-deflection tests, the ISO norms indicate the three-point bending test as the most appropriate.

The deflection test utilized a device fabricated to allow one-point deflection using two brackets (interbracket distance of $10 \mathrm{~mm}$ ) (Figure 1). The device had a 10-mm- diameter acrylic rod adapted to a metallic frame. During the tests, a specially designed jig made of acrylic was bonded onto the machine's support. Edgewise brackets $(0.018 \times 0.025$-in. slot) without angulation or torque (Twin mini, Morelli, Sorocaba, Brazil) were bonded to the acrylic jig. A segment of $0.017 \times 0.025$-in. wire was used to set the two brackets parallel for the first part of the experiments. In order to simulate a clinical situation of misaligned teeth, during the second part of the experiment, a 2-mm horizontal displacement of the brackets was incorporated (Figure 2).

The test wire specimens were fixed on the bracket with elastomeric ligature (Morelli, Sorocaba, Brazil). Six different $0.017 \times 0.025$-in. beta-titanium alloy wires, $30 \mathrm{~mm}$ in length and marketed by five companies, were tested (Table 1). With regard to the Orthometric brand, we analyzed two types of wires (the Orthometric Beta Flexy which is composed of a singular beta-titanium alloy wire and the Orthometric Flexy Multi which combines a betatitanium alloy wire with a nickel-titanium one).

The same investigator cut all wire segments with the aid of a digital caliper (Mitutoyo, Japan). ISO Norm 15.841 advocates a wire sample of at least six specimens, in order to possess a greater certainty in the results observed. Ten specimens of each wire [4] were placed individually in the bracket slot and ligated with a ligature wire. After securing each wire specimen, the acrylic rod was attached to the support utilized for the deflection test. Loading was achieved through movement of a metal loading device adapted on a universal mechanical testing machine (Emic, DL 2000, São José dos Pinhais, Brazil) with a 5-kg load cell and a crosshead speed of $0.5 \mathrm{~mm} / \mathrm{min}$ [12].

A total of 60 segments of $0.017 \times 0.025$-in. $\beta$-Ti wires were tested. The midportion of the test wire specimen was deflected. Forces of the deflection tests were measured in intervals as follows: $0.5,1,1.5$, and $2 \mathrm{~mm}$. The evaluations of the load-deflection of the wires were considered the unloading forces. Forces necessary for the deformation test were recorded directly into the computer
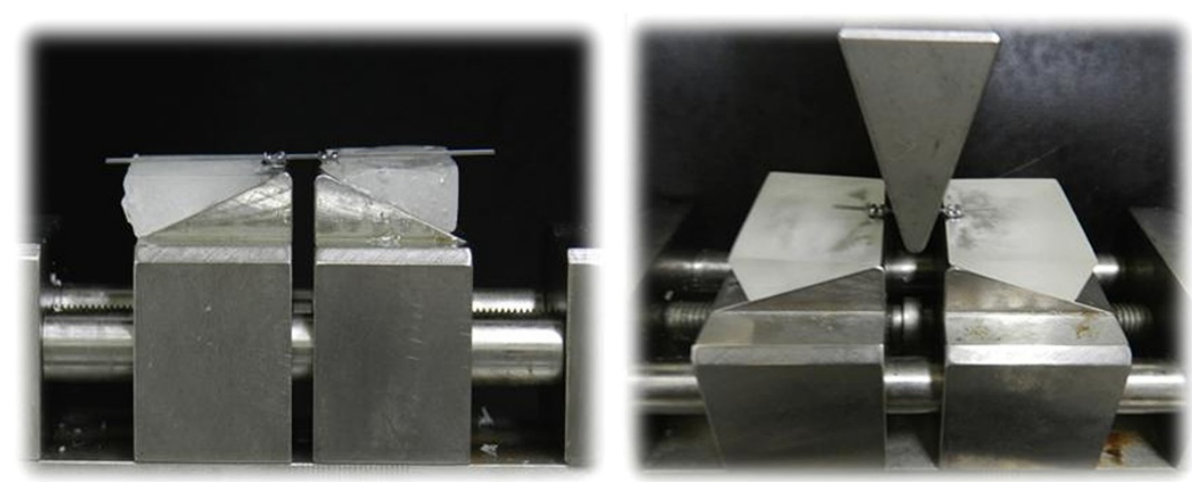

Figure 1 Three-point bending test showing the deflection of the wire with aligned brackets. 


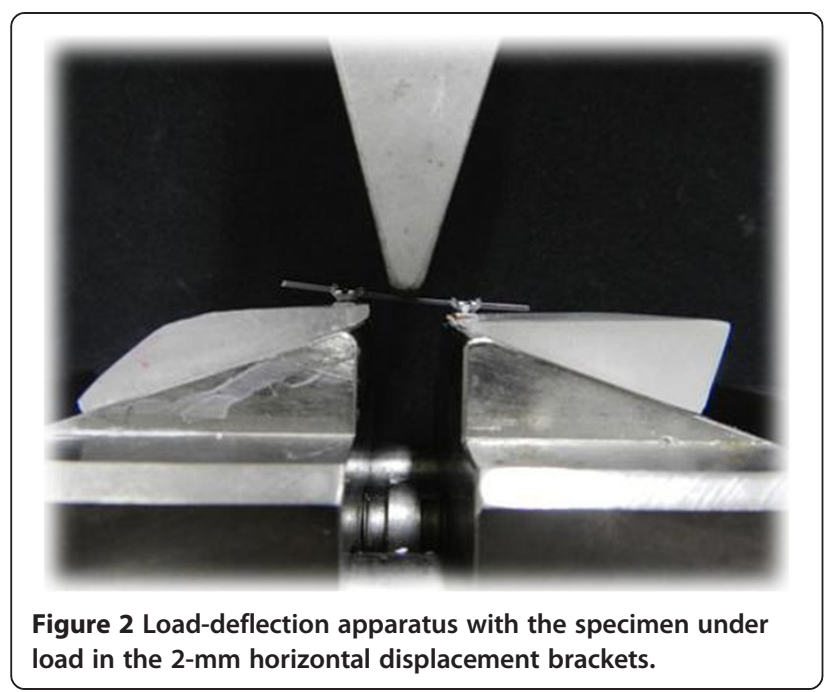

using a Tesc version 3.04 software, Copyright ${ }^{\text {c. }}$ 1998-2005 Mattest Automação e Informática Ltda.

An activation deflection of $1 \mathrm{~mm}$ was selected to establish a comparison parameter [4,6,13-15] at the midpoint of the loading deflection used in this study. According to the ISO 15.841 standard, the test deflection of the wire should be evaluated from 0.5 to $0.5 \mathrm{~mm}$.

\section{Statistical analysis}

Means and standard deviations of the forces generated during the unloading by the $1-\mathrm{mm}$ deflection were selected for the statistical comparison of the data $[6,10,13]$. In order to verify a normal distribution of the data, a Kolmogorov-Smirnov test was used. The results of this test demonstrated that data showed a normal distribution. Therefore, data were analyzed through the parametric analysis of variance (ANOVA) test followed by Tukey test. In all tests, a 5\% level of significance was adopted $(p<0.05)$. The statistical procedures were carried out in the software Statistica version 12 (StatSoft Inc., Tulsa, USA).

\section{Results}

Means and standard deviations of the modulus of elasticity during the activation of the three-point bending test are listed in Table 2. The modulus of elasticity during the
Table 2 Means and standard deviations of modulus of elasticity during the activation of three-point bending test

\begin{tabular}{lcc}
\hline Commercial brand & \multicolumn{2}{c}{ Three-point bending test (GPa) } \\
\cline { 2 - 3 } & Mean & SD \\
\hline GAC & $32.98 \mathrm{a}$ & 1.13 \\
Morelli & $45.58 \mathrm{c}$ & 9.45 \\
Ortho Organizers & $34.16 \mathrm{ab}$ & 2.15 \\
Ormco & $37.89 \mathrm{bc}$ & 7.12 \\
Orthometric (Beta Flexy) & $41.33 \mathrm{c}$ & 3.22 \\
Orthometric (Flexy Multi) & $33.01 \mathrm{a}$ & 5.82 \\
P value & & \\
\hline
\end{tabular}

*Statistically significant differences $(p<0.05)$. Similar letters represent non-significant differences.

activation of the three-point bending test showed a statistically significant difference between the brands. One that presented the highest value was Morelli (45.58 GPa), showing a higher wire stiffness wire, and the lowest value was GAC (32.98 GPa) along with Orthometric Flexy Multi (33.01 GPa) and Ortho Organizers (34.16 GPa) brands. These brands showed a lower wire stiffness.

Means and standard deviations of the 1-mm deflection activation force between leveled and unleveled brackets can be seen in Table 3. The ANOVA test showed a difference between the manufacturers of beta-titanium wires when comparing between the brands. These differences in the brackets leveled were up to $70 \mathrm{~g}$ from a range between $110 \mathrm{~g}$ (Orthometric Flexi Multi) to $179 \mathrm{~g}$ (Morelli). During the activation of the wires, the lowest released force at the 1-mm deflection occurred for the brand Orthometric Flexy Multi. The Ormco, Ortho Organizers, and GAC did not differ from each other (range between 139 and $147 \mathrm{~g}$ ). On the other hand, the brands Morelli and Orthometric Beta Flexy showed the greatest forces in load-deflection behavior, but they did differ from each other. However, in unleveled bracket results, the lowest released force was the Orthometric Flexy Multi brand that differed from Ormco. The latter did not present any differences from the brands Ortho Organizers, GAC, and Orthometric Beta Flexy (range between 139 and 142 g). Morelli showed the greatest force in load-deflection behavior (175 g).

Table 1 Manufacturers, commercial names, and codes of beta-titanium wires tested

\begin{tabular}{lccc}
\hline Manufacturer & Commercial name & Code/material (N) & Lot number \\
\hline GAC, Islip, NY, USA & Resolve & TMA (10) & F1013282 \\
Morelli, Sorocaba, SP Brazil & Beta III & TiMo (10) & 1519074 \\
Ormco, Glendora, CA, USA & TMA & TMA (10) & 8 F106F \\
Orthometric, Marília, SP, Brazil & Flexy Multi & TMA-NiTi (10) & 1109 \\
Orthometric, Marília, SP, Brazil & Beta Flexy & TMA (10) & 000149 \\
Ortho Organizers, Carlsbad, CA, USA & CNA Beta & Beta CNA (10) & F1018428 \\
\hline
\end{tabular}

All the groups were tested at a controlled temperature of $25^{\circ} \mathrm{C}, \mathrm{SD} \pm 1$. 
Table 3 Comparison of load/deflection behavior between leveled and unleveled brackets during a 1-mm deflection in activation evaluation

\begin{tabular}{llcc}
\hline Commercial brand & \multicolumn{2}{c}{ Activation } \\
\cline { 2 - 4 } & & Mean (g) & SD \\
\hline Leveled & Ortho Organizers & $142.40 \mathrm{~b}$ & 2.71 \\
& Morelli & $179.47 \mathrm{~d}$ & 3.02 \\
& GAC & $147.15 \mathrm{~b}$ & 2.06 \\
& Orthometric (Beta Flexy) & $160.39^{*} \mathrm{C}$ & 11.81 \\
& Orthometric (Flexy Multi) & $110.25 \mathrm{a}$ & 6.03 \\
& Ormco & $139.62^{*} \mathrm{~b}$ & 6.18 \\
\multirow{4}{*}{ Unleveled } & $140.15 \mathrm{C}$ & 1.16 \\
& Ortho Organizers & $175.68 \mathrm{~d}$ & 5.10 \\
& Morelli & $139.38 \mathrm{C}$ & 3.80 \\
& GAC & $142.44^{*} \mathrm{C}$ & 13.27 \\
& Orthometric (Beta Flexy) & $111.05 \mathrm{a}$ & 8.60 \\
& Orthometric (Flexy Multi) & $128.84^{*} \mathrm{~b}$ & 7.22 \\
\hline
\end{tabular}

*Statistically significant differences $(p<0.05)$. Different lowercase letters represent non-significant differences.

Comparing the scenarios, only Orthometric Flexy Multi and Ormco brands showed a statistically significant difference among the groups.

The values obtained by ANOVA test in the comparison of the load/deflection behavior between leveled brackets and unleveled brackets during a 1-mm deflection in deactivation are shown in Table 4. For the leveled-type scenario, these differences were also up to $60 \mathrm{~g}$ from a range between 3 to $64 \mathrm{~g}$. The highest force release during the deactivation was the Ormco (64 g)

Table 4 Comparison of load/deflection behavior between leveled and unleveled brackets during a 1-mm deflection in deactivation evaluation

\begin{tabular}{llcc}
\hline Commercial brand & \multicolumn{2}{c}{ Deactivation } \\
\cline { 3 - 4 } & & Mean $(\mathbf{g})$ & SD \\
\hline Leveled & Ortho Organizers & $56.65 \mathrm{c}$ & 1.82 \\
& Morelli & $3.18^{*} \mathrm{a}$ & 0.61 \\
& GAC & $57.99 \mathrm{~cd}$ & 1.21 \\
& Orthometric (beta Flexy) & $3.54 \mathrm{a}$ & 1.26 \\
& Orthometric (Flexy Multi) & $37.32 \mathrm{~b}$ & 6.42 \\
\multirow{4}{*}{ Unleveled } & $64.08 \mathrm{~d}$ & 1.75 \\
& Ormco & $59.10 \mathrm{c}$ & 0.69 \\
& Ortho Organizers & $13.71^{*} \mathrm{a}$ & 1.05 \\
& Morelli & $62.06 \mathrm{~cd}$ & 1.43 \\
& GAC & $9.61 \mathrm{a}$ & 4.31 \\
& Orthometric (beta Flexy) & $34.09 \mathrm{~b}$ & 1.45 \\
& Orthometric (Flexy Multi) & $68.29 \mathrm{~d}$ & 2.61 \\
\hline
\end{tabular}

*Statistically significant differences $(p<0.05)$. Different lowercase letters represent non-significant differences. that did not differ from GAC and Ortho Organizers. This shows that the two aforementioned wires showed the best spring back behavior. On the other hand, brands Morelli and Orthometric Beta Flexy showed the lowest force during the deactivation. For the unleveled-type scenario, they showed the same amount of force between the brands. In the comparison of scenarios, only Morelli brand showed statistically significant difference between the groups.

Table 5 shows the mean and standard deviation when comparing brands and scenarios for the plastic deformation. In the leveled brackets, the brands Ormco, Ortho Organizers, GAC, and Orthometric Flexy Multi showed the best values of plastic deformation and did not show statistically significant difference among them. However, Morelli and Orthometric Beta Flexy demonstrated the worst values among the brands without differences between each other. The results obtained in unleveled brackets showed that Ormco and GAC have the best results; however, they did not differ from the Ortho Organizers and Orthometric Flexy Multi, which also did not differ from Morelli. The latter did not differ from Orthometric Beta Flexy. Only Orthometric Flexy Multi did not show statistically significant difference between the two scenarios.

\section{Discussion}

It is well known that an archwire for any given clinical situation is selected taking into account the mechanical properties of the alloy. Ideal archwires should possess a good balance of stability, stiffness, resilience, and formability [2]. Beta-titanium alloy wires have been widely used in orthodontic practice because of their favorable

Table 5 Mean and standard deviation values (in $\mathrm{mm}$ ) in leveled and unleveled bracket scenarios for plastic deformation

\begin{tabular}{llcc}
\hline Commercial brand & \multicolumn{2}{c}{ Plastic deformation $(\mathbf{m m})$} \\
\cline { 3 - 4 } & & Mean & SD \\
\hline Leveled & GAC & $0.53^{*}$ & 0.00 \\
& Morelli & $0.97^{*}$ & 0.00 \\
& Organizers & $0.53^{*}$ & 0.00 \\
& Ormco & $0.50^{*}$ & 0.02 \\
& Orthometric (beta Flexy) & $0.98^{*}$ & 0.02 \\
& Orthometric (Flexy Multi) & 0.55 & 0.08 \\
& GAC & $0.43^{*}$ & 0.02 \\
& Morelli & $0.90^{*}$ & 0.00 \\
& Organizers & $0.46^{*}$ & 0.00 \\
& Ormco & $0.36^{*}$ & 0.02 \\
& Orthometric (beta Flexy) & $0.92^{*}$ & 0.03 \\
& Orthometric (Flexy Multi) & 0.53 & 0.12
\end{tabular}

*Statistically significant differences $(p<0.05)$ for the same wire. 
characteristics such as low stiffness, excellent formability, and efficiency in tooth movement. The results of the present study support the stated kinder nature of betatitanium archwires when compared to similar values reported for stainless steel alloys $[3,11,15,16]$.

In this study, a three-point bending test was performed to evaluate the load-deflection property, which is one of the most important parameters in determining the biologic response of tooth movement $[13,17]$. Clinicians appeared to be concerned with knowing what force is produced by the wire in relation to the amount of deflection $[13,18]$.

This in vitro test was conceived to simulate a deflection that should induce dental movement. The betatitanium alloy wires showed varied values of modulus of elasticity during activation. Some brands certainly showed a greater modulus of elasticity than others. GAC, Ortho Organizers, Ormco, and Orthometric Flexy Multi showed the lowest values of the modulus of elasticity in the threepoint bending test, i.e., had the lowest stiffness of the beta-titanium wires. These brands, therefore, may be required in clinical situations that need loops, such as Tloop or mushroom loop archwires [19,20]. Our study showed that clinically, one can assume that the lower the stiffness, the better the TMA wire (Ormco, Glendora, CA, USA) and also the better the spring back effect.

The tested beta-titanium alloy wires showed a statistically significant difference in load/deflection behavior and indicate that different forces exist for the same amount of deflection even though the 'same' alloy is used. Among the six types of archwires analyzed during an activation of $1 \mathrm{~mm}$ in both scenarios, the brands Orthometric Flexy Multi, Ormco, Ortho Organizers, and GAC showed the lowest values of force. Overall, all the brands tested showed an adequate force for dental movement [21]. At the same time, the archwires analyzed during the deactivation of $1 \mathrm{~mm}$ in both scenarios, Ormco, GAC, and Ortho Organizers, showed that they are the best wires for this behavior; they demonstrated the greatest forces. Further confirming this, the plastic deformation analysis showed the same tendencies, including those for the Orthometric Flexy Multi which showed the best results. Clinically, the wires that had the greatest values in deactivation are considered better because they can increase the duration time of tooth movement, reducing the final treatment time.

The beta-titanium alloy wires showed plastic deformation during activation. The force-deflection curves distinguished wires that exhibited more plastic deformation than others (Figure 3). The brands Morelli and Orthometric Beta Flexy required greater force to deflect and had more plastic deformation at the end of the deactivation curve. Therefore, it is advisable that these beta-titanium alloy wires would be selected for clinical situations that require bends in the archwire, i.e., loop springs or cantilever.

All beta-titanium alloy wires tested exhibited statistical differences, indicating the existence of different forces for the same amount of deflection when using different commercially available wires. Among the six types of wires analyzed in both activation and deactivation phases, only Morelli and Orthometric Beta Flexy wires exhibited forces different from the others. These two brands exhibited the highest force on activation, indicating that Morelli and Orthometric Beta Flexy have higher stiffness during deflection. At a deactivation deflection of $1 \mathrm{~mm}$, Morelli produced a force of $3.18 \mathrm{~g}$. This force is not enough to induce the biological response needed to produce dental movement in most patients [21]. The Orthometric Flexy Multi, wire showed forces different from those of the other wires tested. Also, Ormco, Ortho Organizers, and GAC wires showed low forces with activation of $1 \mathrm{~mm}$.

The flexibility and the load/deflection relationship depend on the modulus of elasticity [22]. The lower this relationship, the more constant is the force that makes a

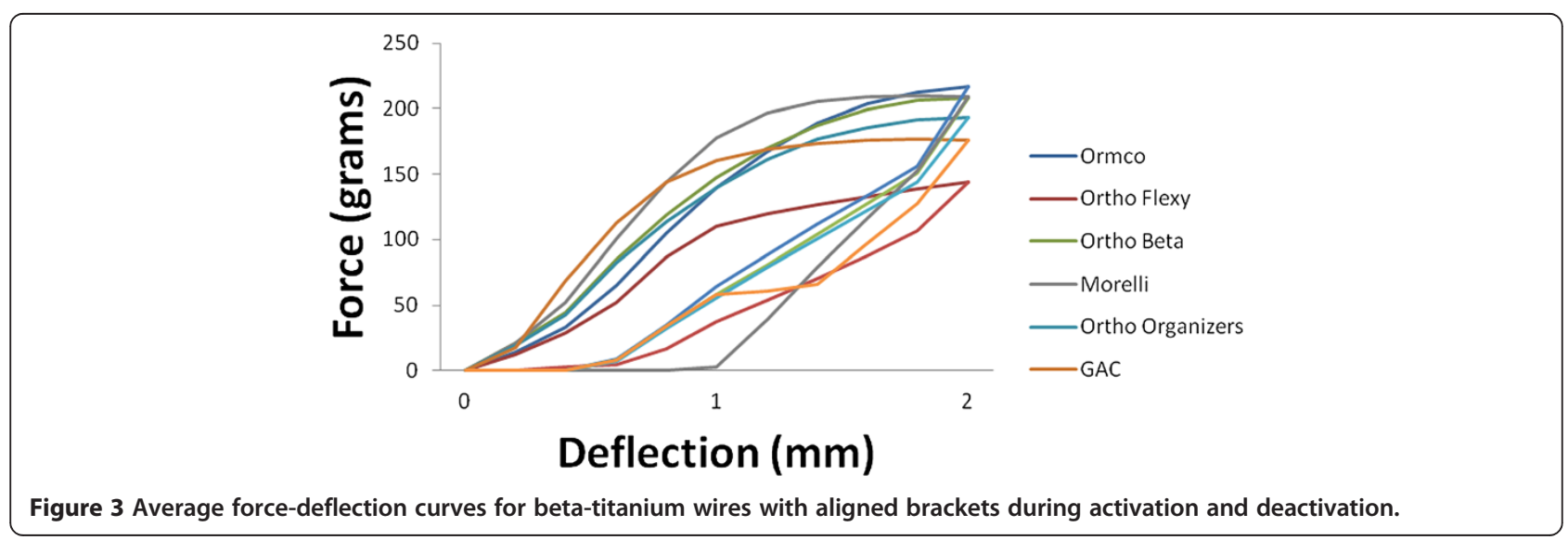


tooth move. With a variation of the modulus of elasticity of the wires, progressive stiffness of the archwires may be achieved without altering the cross section of the wires and have, as advantages, the use of rectangular wires in the first stages of treatment, guidance as to the choice or the wires, and less frequent changes [22].

The representative bending plots for the forcedeflection curves of wires with unleveled brackets (Figure 4) showed that only Morelli did not show a statistically significant difference between leveled and unleveled brackets for the deactivation. Regarding activation, only Orthometric Flexy Multi and Ormco did not show statistically significant difference. Moreover, great similarity between the curves displayed for both manufacturers can be seen. Also, only Orthometric Flexy Multi needed less force to deflect.

Undoubtedly, the wires that need lower forces to deflect represent a favorable characteristic for dental movement and can be successfully used in the control of the system of forces between tooth and periodental structures. It is worth mentioning that future studies with different displaced bracket distances and directions are required to complement the results of this study. The clinical importance of such differences remains unclear, but an argument can be made that almost $100 \mathrm{~g}$ (lowest against highest force values) difference should no be easily clinically dismissed.

\section{Limitations}

Laboratory (in vitro) tests do not necessarily reflect clinical situations, but these tests provide a basis for comparison of different wires and have been used in many studies in the literature. These tests may be used as stepping stones to better justify more expensive clinical studies. The results from such in vitro tests should be further tested whenever possible in clinical trials [23].
Orthodontic tooth movement occurs when a force is exerted on teeth. In this study, we assessed a deflection force of $2 \mathrm{~mm}$ and results obtained from this degree of displacement. The brackets were unleveled to produce a clinical situation where there is presence of unleveled teeth. In this situation, there is a larger friction in brackets by changing the force required for the displacement, therefore if the values differ from the values found in a situation of a classic three-point bending test. If this deflection force is larger than $2 \mathrm{~mm}$, it may produce different forces and consequently also different results. The type of ligation may have an effect. Only ligature wires where used. Finally, the effects when more than two brackets are considered were not evaluated.

\section{Conclusions}

The following conclusions are drawn from the study:

- The study showed significant differences in force during activation and deactivation among the five types of beta-titanium wires tested.

- In comparing leveled and unleveled brackets during activation, only Orthometric Beta Flexy and Ormco Beta-titanium wires show a statistically significant difference between them. In the deactivation part, only Morelli titanium alloy wire showed a statistically significant difference.

- Among the commercial brands studied, those that showed the best behavior in their capacity to maintain an elastic memory in the three-point bending test were as follows: Ormco, GAC, Ortho Organizers, and Orthometric Flexy Multi Betatitanium wires.

- The behavior of the load-deflection relationship showed that Ormco, Ortho Organizers, and GAC Beta-titanium wires obtained the best force values during deactivation.

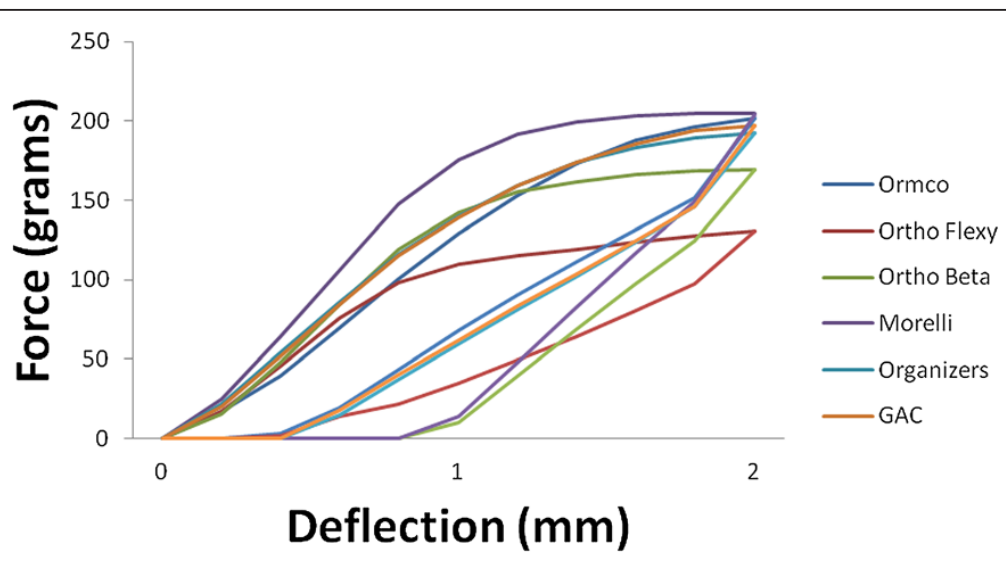

Figure 4 Average force-deflection curves for beta-titanium wires with 2-mm displacement brackets during activation and deactivation. 


\section{Competing interests}

The authors declare that they have no competing interests.

\section{Authors' contributions}

NMI carried out the study; TP, ACC and PVON provided statistical support, MML provided the 3 point bend test machine setup, CFM provided input to the 3 point bending test behavior setup and MRA was the advisor of the MSC thesis by NMI and drafted the manuscript; All authors read and approved the final manuscript.

\section{Author details}

'Department of Orthodontics, University of North Parana, UNOPAR, Londrina, Paraná, Brazil. ${ }^{2}$ Department of Restorative Dentistry and Biomaterials, University of North Parana, Londrina, PR, Brazil. ${ }^{3}$ Division of Orthodontics, University of Alberta, Edmonton, Alberta, Canada.

Received: 11 March 2014 Accepted: 21 April 2014

Published online: 30 May 2014

\section{References}

1. Kapila S, Sachdeva R. Mechanical properties and clinical applications of orthodontic wires. Am J Orthod Dentofacial Orthop. 1989; 96(2):100-9.

2. Goldberg AJ, Burstone CJ. An evaluation of beta titanium alloys for use in orthodontic appliances. J Dent Res. 1979; 58(2):593-9.

3. Burstone CJ, Goldberg AJ. Beta titanium: a new orthodontic alloy. Am J Orthod. 1980; 77(2):121-32.

4. Juvvadi SR, Kailasam V, Padmanabhan S, Chitharanjan AB. Physical, mechanical, and flexural properties of 3 orthodontic wires: an in-vitro study. Am J Orthod Dentofacial Orthop. 2010; 138(5):623-30.

5. Sifakakis I, Pandis N, Makou M, Eliades T, Bourauel C. A comparative assessment of the forces and moments generated with various maxillary incisor intrusion biomechanics. Eur J Orthod. 2010; 32(2):159-64.

6. Gurgel JA, Kerr S, Powers JM, LeCrone V. Force-deflection properties of superelastic nickel-titanium archwires. Am J Orthod Dentofacial Orthop. 2001; 120(4):378-82.

7. Quintão CC, Cal-Neto JP, Menezes LM, Elias CN. Force-deflection properties of initial orthodontic archwires. World J Orthod. 2009; 10(1):29-32.

8. Andreasen GF, Hilleman TB. An evaluation of 55 cobalt substituted nitinol wire for use in orthodontics. J Am Dent Assoc. 1971; 82(6):1373-5.

9. Drake SR, Wayne DM, Powers JM, Asgar K. Mechanical properties of orthodontic wires in tension, bending, and torsion. Am J Orthod. 1982; 82(3):206-10.

10. Keim RG, Gottlieb EL, Nelson AH, Vogels DS 3rd. 2008 JCO study of orthodontic diagnosis and treatment procedures, part 1: results and trends. J Clin Orthod. 2008; 42(11):625-40.

11. Burstone CJ. JCO interviews on orthodontic force control. J Clin Orthod. 1981; 15(4):266-78.

12. Gurgel JA, Pinzan-Vercelino CR, Powers JM. Mechanical properties of beta-titanium wires. Angle Orthod. 2011; 81(3):478-83.

13. Krishnan V, Kumar KJ. Mechanical properties and surface characteristics of three archwire alloys. Angle Orthod. 2004; 74(6):825-31.

14. Nakano H, Satoh K, Norris R, Jin T, Kamegai T, Ishikawa F, Katsura H. Mechanical properties of several nickel-titanium alloy wires in threepoint bending tests. Am J Orthod Dentofacial Orthop. 1999; 115:390-5.

15. Kusy RP, Stush AM. Geometric and material parameters of a nickeltitanium and a beta titanium orthodontic arch wire alloy. Dent Mater. 1987; 3(4):207-17.

16. Bartzela TN, Senn C, Wichelhaus A. Load-deflection characteristics of superelastic nickel-titanium wires. Angle Orthod. 2007; 77(6):991-8.

17. Burstone CJ. Variable-modulus orthodontics. Am J Orthod. 1981; 80(1):1-16.

18. Kokich VG. What a year! Am J Orthod Dentofacial Orthop. 2012; 141(1):1.

19. Uribe F, Nanda R. Treatment of class II, division 2 malocclusion in adults: biomechanical considerations. J Clin Orthod. 2003; 37(11):599-606.

20. Nanda R. Biomechanics and Esthetic Strategies in Clinical Orthodontics. St. Louis: Elsevier Saunders; 2005.
21. Proffit WR, Fields HW, Sarver DM. The biologic basis of orthodontic therapy. In: Contemporary Orthodontics. 4th ed. St. Louis: CV Mosby; 2006: p. 331-58.

22. Burstone CJ, Van Steenbergen E, Hanley KJ. Modern Edgewise Mechanics and the Segmented Arch Technique. Farmington: Ormco Corporation; 1995: p. 4.

23. Mohlin B, Muller H, Odman J, Thilander B. Examination of Chinese NiTi wire by a combined clinical and laboratory approach. Eur J Orthod. 1991; 13:386-91.

doi:10.1186/s40510-014-0042-0

Cite this article as: Insabralde et al:: Comparison of mechanical properties of beta-titanium wires between leveled and unleveled brackets: an in vitro study. Progress in Orthodontics 2014 15:42.

\section{Submit your manuscript to a SpringerOpen ${ }^{\odot}$ journal and benefit from:}

- Convenient online submission

- Rigorous peer review

- Immediate publication on acceptance

- Open access: articles freely available online

- High visibility within the field

- Retaining the copyright to your article

Submit your next manuscript at $>$ springeropen.com 